\title{
Effects of activity modification on the patients with osteoarthritis of the knee
}

\author{
M. A. Shakoor ${ }^{1}$, Md. Abu Taslim² and Md. Shahadat Hossain² \\ ${ }^{1}$ Department of Physical Medicine and Rehabilitation, Bangabandhu Sheikh Mujib Medical University, \\ Dhaka, Bangladesh; ${ }^{2}$ Department of Physical Medicine, Chittagong Medical College, \\ Chittagong, Bangladesh. e-mail: dmashakoor04@yahoo.com
}

\begin{abstract}
A prospective randomized clinical trial was conducted on 162 patients of osteoarthritis of knee were included in the study. The patients were divided into two groups- Group A and Group B. The Group A was treated with shortwave diathermy, exercise, naproxen and activity modification and the Group B was treated with shortwave diathermy, exercise and naproxen. Improvement was found more in Group A than Group B after $4^{\text {th }}$ week (95 \% CI was -2.59 to 6.56). Then it was found that the improvement was gradually increased in Group A than Group B and finally, it was found that there was highly significant improvement in Group A than Group B after $6^{\text {th }}$ week (95 \% CI was -3.45 to -0.70 ). This study suggests that activity modification play an important role for the treatment of the patients with osteoarthritis of knee.
\end{abstract}

\section{Introduction}

Osteoarthritis is the most important of the rheumatic diseases and is responsible for a huge burden of pain and disability ${ }^{1}$. Osteoarthritis is characterized by both degeneration of articular cartilage and simultaneous proliferation of new bone, cartilage, and connective tissue ${ }^{2}$. It is the most prevalent form of arthritis and is the principal cause of disability in the elderly ${ }^{3-6}$. The area of local damage occurs in those parts of the joint subjected to maximal mechanical stretch ${ }^{7}$. Mild osteoarthritis of the knee is extremely common, mainly affecting middle aged and elderly women ${ }^{8}$.

The knee is a complex joint, with three major compartments: the medial and lateral tibio-femoral joints and the patello-femoral joint ${ }^{9}$. Pain on walking, stiffness of the joint and difficulty with steps and stairs are the major symptoms. The physical signs depend on the distribution and severity of the osteoarthritis within the joint. Wasting of the quadriceps muscle, bony swelling, and tenderness on and around the joint line, painful limitation of full flexion and course crepitus are the usual signs.

A wide variety of treatments are available for those who suffer from osteoarthritis of the knee and self- management, weight reduction, hydrotherapy, footwear and walking aids, other rehabilitation measures, physical therapy, systemic drug therapy, intra-articular drug therapy and surgery ${ }^{7-13}$. Much can be done to relief symptoms, optimize function and improve the quality of life. But no specific therapy has been proven to have efficacy in alternating the disease process in human ${ }^{8}$. A recent study shows that isometric resistance training improves functional ability and reduces knee joint pain with patients of knee osteoarthritis ${ }^{14}$. Didactic advice on activity and exercise is often given, but the amount of activity that patient should be advised to take remains controversial ${ }^{8,9}$.

A suitable activity modification, i.e. activities of daily living instructions, exercises, and physical therapy is essential for the patients suffering from osteoarthritis of the knee to reduce symptoms and disability. By which, the patients may be able to do their normal activities and be able to contribute themselves for the prosperity of the society. For this purpose, we observed the effects of activity modification on osteoarthritis of the knee to improve the present situation regarding management and to reduce the disability of the patients so that they can contribute more time for the prosperity of the country. 


\section{Materials and Methods}

The patients having osteoarthritis of the knee were selected from the out-patient departments from May 2003 to April 2004. On arrival, detailed history was taken and clinical examination and necessary investigations were carried out properly. The patients were selected according to the criteria developed by the American College of Rheumatology ${ }^{15}$ In total 162 patients were selected for the study according to the selection criteria. They were divided into two groups randomly by the way of lottery. Group A: In this group 83 patients were treated with activity modification, shortwave diathermy, exercise and NSAID. Group B: In this group 79 patients were treated with shortwave diathermy, exercise, and NSAID.

Naproxen (250 mg) was given twice daily in both the groups. Shortwave diathermy and exercise (isometric quadriceps muscle strengthening exercise five repetition twice daily) were given in both the group. Instruction in activities of daily living for activity modification was provided in local language (Bangla) in the Group A only. On the other hand, assistive devices like knee cap, walking stick, high commode was provided to the patients for proper maintenance of activities of daily living in Group A. Activities of daily living were: 1) not to bent the knee more than 90 degree; 2) to use walking stick on the opposite hand of the affected knee/more painful knee joint during walking; 3) to climb a stair, use the handle of the stair and climb slowly and the body weight should be transferred to the handle by the hand opposite to the affected knee / more affected knee; 4) to reduce body weight for overweight person; 5) to use high commode in bathroom, dining table for eating and knee cap during activity; 6) to avoid high healed shows, sitting in pera and mora (Bengali name of low sitting stool), prolonged walking/sitting/ running, tube well handling for collecting water and soft and non sagging mattress; 7) to cook in standing position and if necessary to site in a chair for a while; 8) to bath in standing or sitting position with a shower and not to take water from a pot by kneeling.

Before admission into the trial the nature of the study was discussed with the patients and informed consent of the patients was taken. History, clinical examination and relevant investigations were done. The findings were recorded at first attendance and follow-up was done weekly for six weeks and all the findings were recorded weekly. The following parameters were used for comparing the treatment: Visual Analogue Scale (VAS) ${ }^{16}$, the Lattinen test ${ }^{17}$ and Range of Motion (ROM) of the knee joints.
The pain VAS presented to patients was a $10 \mathrm{~cm}$ horizontal line with end points of 'no pain' $=0$ and 'maximum pain' $=10$ and patients were asked to rate how bad their pain was by placing a mark somewhere along the scale between these two extremes. The Lattinen test score contains 0 to 4 marks for subjective intensity of pain, frequency of pain, analgesic intake for pain, disability due to pain and sleep disturbance for pain. The score increased according to the severity. The summation of the all these scores were done for analysis.

Statistical methods: The numerical data were analyzed statistically. The results were expressed as mean \pm SD and the level of significant was expressed by confidence interval unless otherwise stated. Statistical analysis was done by using SPSS package for Windows. Student's ' $t$ ' tests were done to test the hypothesis.

\section{Results}

A total of 162 patients follow the treatment allocated for them properly. Out of them, 96 (59.3\%) were male and 66 (40.7\%) were female and male: female ratio was $1: 0.68$. The mean age of the patients was $53.7 \pm 11.3$ years. Before admission into the trial baseline criteria of the patients of the two groups were compared and it was found identical. There was significant improvement after treatment in Group A. In respect to time point improvement, marked improvement was started to occur after one week and the improvement gradually increased day by day. After the end of treatment there was highly significant improvement found. This indicates that treatments with shortwave diathermy plus exercises plus activities of daily living instructions were effective. There was significant improvement after treatment in Group B also. In respect to time point improvement, marked improvement was started to occur after one week. The improvement gradually increased day by day and after the end of treatment highly significant improvement was found. This indicates that treatment with shortwave diathermy plus exercises without activities of daily living instructions was also effective for the treatment of the patients with osteoarthritis of the knee. Regarding range of motion, it was found that there was significance improvement after treatment in the same group. But in comparison between two groups, there was no significant difference in improvement of ROM between two groups after treatment for 6 weeks.

In comparison between two groups, it was found that there was no significant difference in pre- 
treatment, $\mathrm{W}_{1}, \mathrm{~W}_{2}$ and $\mathrm{W}_{3}$, assessment scores between the two groups i.e. there was no difference in improvement. More improvement was found in Group A than Group B after $4^{\text {th }}$ week. It was found that the improvement was gradually increased in
Group A than Group B and finally, there was highly significant improvement in Group A than Group B after six weeks (95\% CI, -3.45 to -0.70 ; Table I).

Table I: Comparative improvement of symptoms between Group A and Group B in different time points

\begin{tabular}{lccccccc}
\hline Group & Score at $\mathbf{W}_{\mathbf{0}}$ & Score at $\mathbf{W}_{\mathbf{1}}$ & Score at $\mathbf{W}_{\mathbf{2}}$ & Score at $\mathbf{W}_{\mathbf{3}}$ & Score at $\mathbf{W}_{\mathbf{4}}$ & ${\text { Score at } \mathbf{W}_{\mathbf{5}}}^{\text {Score at } \mathbf{W}_{\mathbf{6}}}$ \\
\hline $\mathrm{A}(\mathrm{n}=83)$ & $14.98 \pm 3.53$ & $13.21 \pm 3.68$ & $11.96 \pm 3.86$ & $10.75 \pm 3.96$ & $9.64 \pm 4.08$ & $8.53 \pm 3.94$ & $7.70 \pm 4.07$ \\
$\mathrm{~B}(\mathrm{n}=79)$ & $13.84 \pm 3.76$ & $12.90 \pm 3.84$ & $12.23 \pm 4.03$ & $11.71 \pm 4.20$ & $10.93 \pm 4.28$ & $10.09 \pm 4.37$ & $9.77 \pm 4.73$ \\
$95 \%$ CI & 7.29 to 2.27 & -0.86 to 1.48 & -1.49 to 0.96 & -2.23 to 0.31 & -2.59 to 6.56 & -2.86 to -0.27 & -3.45 to -0.70 \\
\hline
\end{tabular}

The results are expressed in mean \pm SD. $n=$ Number of the patients participated in the clinical trial; $\mathrm{W}=$ week

\section{Discussion}

In our study significant improvement of symptoms within both the groups began to appear at the end of first week. But, no significant difference of improvement was found to begin between the groups at this stage. At the end of $4^{\text {th }}$ week significant improvement was observed between the groups. The trends of improvements were continued throughout the whole period of six weeks of study. At the end of $6^{\text {th }}$ week significant improvement of symptoms in both the groups were found.

In comparison between the two groups, the significant improvement was found in the group of patients who received short wave diathermy plus activity modification than that of the patients who were not given activity modification. Jan and Lai found in their study that there was significant improvement after treatment with ultrasound therapy or shortwave diathermy only and ultrasound therapy plus exercise and shortwave diathermy plus exercise ${ }^{18}$. They studied 61 females with osteoarthritis of the knee. This is in favor of our study as we use shortwave diathermy plus exercise in both the group. Quadriceps muscle strengthening exercise is important for increasing of the muscles strength and it is evident that muscle strengthening exercise improves the condition of the patients with osteoarthritis of the knee significantly found in various studies ${ }^{7,19-21}$.

In a study, it was found that home based exercise program can significantly reduce pain in osteoarthritis of the knee ${ }^{11}$. In our study, we also found marked reduction of knee pain in both the groups as we advocated exercise in both the groups. American College of Rheumatology subcommittee also recommends quadriceps strengthening exercise for osteoarthritis of the $\mathrm{knee}^{22}$. Quadriceps weakness is common among patients with osteoarthritis of the knee, in whom it had been believed to be a manifestation of disuse atrophy, which develops because of unloading of the painful extremity $^{23}$. Both quadriceps strengthening exercise and aerobic exercise is recommended for the patient with osteoarthritis of the knee ${ }^{22,24}$. Patient with hip and knee osteoarthritis can participate conditioning exercise programs to improve fitness and health without increasing joint pain or increasing their requirement for analgesic agents or anti-inflammatory drugs ${ }^{23}$. They described the preference of isometric exercises over isotonic exercises. In our study, we also used isometric quadriceps exercise for the treatment of osteoarthritis of the knee. Shortwave diathermy is helpful to improve pain and function of the patient with osteoarthritis of the knee. In a study in India, Bansil and Joshin found shortwave diathermy was effective in the treatment of osteoarthritis of the knee and they showed that shortwave diathermy provides a wider coverage of all structures of the knee than the ultrasonic procedure and thus gives a more effective soothing effect ${ }^{25}$. On the other hand, Svarcova et al., found good to excellent improvement of pain in maximum patients after treatment with shortwave diathermy, ultrasound and galvanic current ${ }^{10}$. These all findings support the results of the present series.

In the present study, improvement was found more in the patients received activity modification. So, activity modification is very much important in the management of osteoarthritis of the knee. Individual with osteoarthritis of the lower extremity may have limitations that impair their ability to perform activities of daily livings, such as walking, bathing, dressing, use of toilet, and household chores $^{21}$. Hui and Marchie stated in a review that rehabilitation, physical therapy and use of a brace may provide short-term relief in osteoarthritis ${ }^{26}$. The sub-committee on the Osteoarthritis Guideline of American College of Rheumatology recommends the use of assistive devise, such as 
canes, crutches or walkers to improve ambulation and proper advice for joint protection, energy conservation and improving joint function ${ }^{21}$. In a review, Chard and Dieppe showed that aids and appliances are moderately effective in reducing pain and improving function without side effects. They found that education and behavioral change was moderately effective on pain and function without side effects ${ }^{7}$. This is also in favor of our study.

In conclusion, it may be concluded that posture correction advice i.e. activity modification is very much helpful for the treatment of osteoarthritis of the knee. Kneecap, walking stick and use of high commode are also helpful for maintaining proper posture and thus to reduce pain and disability of the patients with osteoarthritis of the knee.

\section{Acknowledgements}

We are highly grateful to Bangladesh Medical Research Council for financial support and ethical clearance for the study otherwise it could not be carried out. We are also thankful to the patients for their willful participation in the study.

\section{Authors' contribution}

MAS: Principal investigator of the study and responsible for all activities of the project.

MAT and MSH: Data collector.

\section{References}

1. Dieppe P. Management of osteoarthritis of hip and knee joints. Curr Opin Rheumatol. 1993; 5: 487-93.

2. Doherty M, Lanyon P, Rolston SH. Musculoskeletal disorders. In: Davidson's Principles and practice of medicine. Boon NA, Colledge NR, Walker BR (eds). $20^{\text {th }}$ ed. Edinburgh, Churchill Livingstone, 2006, pp 1065-1144.

3. Lawrence RC, Helmick CG, Arnett FC, Deyo RA, Felson DT, Giannini EH, Heyse SP, Hirsch R, Hochberg MC, Hunder GG, Lai MH, Pillemer SR, Steen VD, Wolfe F. Estimates of the prevalence of arthritis and selected musculoskeletal disorders in the United States. Arthritis Rheum. 1998; 41: 778-99.

4. Towheed TE. The impact of musculoskeletal disorders in Canada. Ann Roy Coll Phys Surg Can 1998; 31: 229-32.

5. Center for Disease Control. Arthritis prevalence and activity limitations- United States. MMWR 1994; 43: 433-38.

6. Creamer P, Hochberg MC. Osteoarthritis. Lancet 1997; 350: 503-9.
7. Chard J, Dieppe P. The case for non-pharmacologic therapy of osteoarthritis. Curr Rheumatol Rep. 2001; 3: 251-57.

8. Altman RD, Lozada CJ. Management of limb joint osteoarthritis. In: Practical rheumatology. Hochberg MC, Silman AJ, Smolen JS, Weinblant ME, Weisman MH (eds). $3^{\text {rd }}$ ed. London, Mosby Publications, 2004, pp 511-19.

9. Altman RD, Lozada CJ. Clinical features. In: Practical rheumatology. Hochberg MC, Silman AJ, Smolen JS, Weinblant ME, Weisman MH (eds). $3^{\text {rd }}$ ed. London, Mosby Publications, 2004, pp 503-10.

10. Svarcova J, Trunavsky, Zvarov AJ. The influence of ultrasound, galvanic currents and shortwave diathermy on pain intensity in patients with osteoarthritis. Scand J Rheumatol. 1988; 67 Suppl: 83S-85S.

11. Thomas KS, Muir KR, Doherty M, Jones AC, O` Reilly SC, Bassey EJ. Home based exercise programme for knee pain and knee osteoarthritis: Randomised controlled trial. BMJ. 2002; 5: 752.

12. Hurley MV, Scott DL. Improvements in quadriceps sensorimotor function and disability of patients with knee osteoarthritis following a classically practicable exercise regime. Br J Rheumatol. 1998; 37: 1181-87.

13. Williams FMK, Spector TD. Osteoarthrities. Med Int. 2006; 34: 364-68.

14. Topp R, Woolley S, Hornyak $\mathrm{J} 3^{\text {rd }}$, Khunder S, Kahaleh B. The effect of dynamic versus isometric resistance training on pain and functioning among adults with osteoarthritis of the knee. Arch Phys Med Rehabil. 2002; 83: 1187-95.

15. Moskowity RW. Clinical and laboratory findings in Osteoarthritis. In: Arthritis and allied condition- A textbook of rheumatology. McCarty JR, Koopman WJ, (eds). Philadelphia-London, Lea and Febiger, 1993, pp 1735-60.

16. de C Williams AC, Davies HT, Chadury Y. Simple pain rating scales hide complex idiosyncratic meanings. Pain 2000; 85: 457-63.

17. Ceballos A, Cabezudo L, Bovaira M, Fendlosa P, Moro B. Spinal cord stimulation: A possible therapeutic alternative for chronic mesenteries ischemia. Pain 2000; 87: 99-101.

18. Jan MH, Lai JS. The effects of physiotherapy on osteoarthritic knees of females. J Formos Med Assoc. 1991; 90: 1008-13.

19. Fisher NM, White SC, Yack HK, Smolinki RJ, Pendergast DR. Muscle function and gait in patients with knee osteoarthritis before and after muscle rehabilitation. Disability Rehabil. 1997; 19: 47-55.

20. Chamberlin MA, Care G, Harfield B. Physiotherapy in osteoarthrosis of the knee: A controlled trial of hospital versus home exercise. Int Rehab Med. 1982; 4: 101-06.

21. Fitzgerald GK, Childs JD, Ridge TM, Irrgang JJ. Agility and perturbation training for physically active individual with knee osteoarthritis. Phys Ther. 2002; 82: 372-82. 
22. Recommendation for the medical management of osteoarthritis of the hip and knee- 2000 update. American College of Rheumatology sub-committee on Osteoarthritis Guidelines. Arthritis Rheum. 2000; 43: 1905-15.

23. Brandt KD. Non-surgical management of osteoarthritis with an emphasis on non-pharmacologic measures. Arch Fam Med. 1995; 4:1057-64.

24. Fisher NM, Kame VD Jr, Rouse L, Pendergast DR. Quantitative evaluation of a home exercise program on muscle and functional capacity of patients with osteoarthritis. Am J Phys Med Rehabil. 1994; 73: 41320.

25. Bansil CK, Joshin JB. Effectiveness of shortwave diathermy and ultrasound in the treatment of osteoarthritis of the knee joint. Med J Zambia 1975; 9: 138-39.

26. Hui JHP, Marchie A. Current management of cartilage defects: A review. APLAR J Rheumatol. 2003; 6: 17077. 